\title{
Experimental and numerical investigations on the flexural performance of geopolymers reinforced with short hybrid polymeric fibres
}

\author{
M. Kheradmand a , M. Mastali a , Z. Abdollahnejad a, F. Pacheco-Torgal a, b, * \\ ${ }^{\text {a } C-T A C}$ Research Centre, University of Minho, Guimarães, Portugal \\ b SHRC, University of Sungkyunkwan, Suwon, Republic of Korea
}

\section{A R T I C L E I N F O}

\section{Article history:}

Received 21 December 2016

Received in revised form

12 April 2017

Accepted 1 June 2017

Available online 8 June 2017

\section{Keywords:}

Waste reuse

Geopolymeric mortars

Fly ash

Flexural

Toughness

Constitutive model

\begin{abstract}
A B S T R A C T
Geopolymers have much higher drying shrinkage than Portland cement based composites Shrinkage performance is an important property for reinforced concrete composites just because a high shrinkage performance is associated to cracking tendency that leads to future durability problems. This paper provides results experimental and numerical investigations of fly ash based geopolymeric mortars reinforced with short hybrid polymeric fibres (SHPF). The results show that SHPF improved the flexural performance, while reducing the compressive strength and flexural stiffness of geopolymeric mortars. The addition of $0.8 \%$ SHPF increased about two times the fracture energy and about 50\% the tensile strength. The adopted constitutive model well-captured the flexural performance of the tested beams.
\end{abstract}

(ㄷ) 2017 Elsevier Ltd. All rights reserved.

\section{Introduction}

Geopolymers are OPC alternative materials produced though the reaction of an aluminosilicate powder with an alkaline activator, usually composed by hydroxide, silicate, carbonate or sulfate leading to the formation an amorphous aluminosilicate gel and secondary nano crystalline zeolite-like structures [1-4]. This materials have a particular ability for the reuse of several types of wastes [5-7]. This is an important feature especially in the European context of a circular economy and zero waste target [8] that may lead to an overall savings potential of $€ 630$ billion per year for European industry and can also create more than 180000 direct jobs in the EU by 2030. Some wastes like fly ash deserve an especial attention because they are generated in high amount and have a very low reuse rate. USA has a reuse rate for fly ash of around 50\% meaning that 30 million tons of fly ash are not reused annually [9]. Other recent works confirm the importance of further studies regarding the development of geopolymers based on fly ash

\footnotetext{
* Corresponding author. C-TAC Research Centre, University of Minho, Guimarães, Portugal.

E-mail address: torgal@civil.uminho.pt (F. Pacheco-Torgal).
}

percursors [10]. Shrinkage performance is an important property for reinforced concrete composites just because a high shrinkage performance is associated to cracking tendency that leads to future durability problems. Some authors [11,12] reported that geopolymers can have much higher autogenous shrinkage than Portland cement based composites that could be explained by the fact that geopolymers showed a much higher mesopores content ( $82 \%$ versus 36\%). Recent investigations confirmed this pore related explanation [13]. The use of fibre reinforcement has the potential to overcome this problem. That is why in the last years several authors studied the mechanical performance of geopolymers reinforced with different fibres [14-17]. However, this area still has many knowledge gaps especially concerning the use of hybrid fibres. Although, some studies have been implemented on using hybrid fibers in reinforcing cement-based composites.

Caggiano et al., in 2016, presented the results of experimental tests regarding the plain concrete reinforced with polypropylene (PP) and steel fibers. Different combinations of hybrid fibers were used to reinforce the plain concrete, and mechanical properties were characterized by using compressive and flexural strengths [44]. It was observed that the effects of fibers on improving the compressive strength, while the post-peak response was significantly governed by the type of fibers [44]. 
Mastali et al. investigated the feasibility of using hybrid PP fiber and recycled steel fiber (RSF) in the self-compacting concrete [45]. The fresh and hardened properties of specimens were studied. The results showed that using hybrid recycled steel-PP fiber improves the impact resistance and mechanical properties. Moreover, as it was expected the addition of recycled steel fiber resulted in recording greater enhancement in the compressive strength, as compared to PP fiber [45].

Martinelli et al. investigated mechanical properties of fiber reinforced concrete containing both virgin (or industrial) and recycled steel fiber (RSF) recovered from waste end-of-life tires [46]. Different contents of industrial and recycled steel fiber (RSF) used to reinforce the plain concrete. The fiber volume fractions for all specimens were considered equal to $0.5 \%$. The results revealed that fibers have a negligible impact on the compressive strength, while higher decay in the post-cracking behavior was recorded in the reinforced specimens by increasing the content of RSF [46].

Caggiano et al. studied the effects of using hybrid long/short steel fibers on the fracture behavior of prismatic concrete beams [47]. The mix compositions were reinforced with employing $0.5 \%$ and $1.0 \%$ of fiber volume fractions. The results indicated that adding hybrid steel fibers had no consistent trend in the response of the fiber-reinforced composites in the post-cracking regime [47].

Thus, regarding the efficiency of hybrid fibers in the literature, this paper established to provide the results on fly ash based geopolymeric mortars reinforced with short hybrid polymeric fibres (SHPF).

\section{Experimental program}

\subsection{Materials}

The raw materials used for the preparation of the geopolymeric mortars were comprised of fly ash, calcium hydroxide, sand, sodium silicate, sodium hydroxide, and fibres. Solid sodium hydroxide was obtained from commercially available product of ERCROS, S.A., Spain, which used to prepare the $\mathrm{NaOH}$ solution. Distilled water was used to dissolve the sodium hydroxide flakes to avoid the effect of unknown contaminates in the mixing water. The $\mathrm{NaOH}$ mix was made one day prior to use in order to have a homogenous solution at the time of mortar preparation. The chemical composition of the sodium hydroxide was composed of $25 \% \mathrm{Na}_{2} \mathrm{O}$ and $75 \%$ $\mathrm{H}_{2} \mathrm{O}$. The sodium silicate liquid was supplied by MARCANDE, Portugal. The chemical composition of the sodium silicate was of $13.5 \% \mathrm{Na}_{2} \mathrm{O}, 58.7 \% \mathrm{SiO}_{2}$, and $45.2 \% \mathrm{H}_{2} \mathrm{O}$. The fly ash was obtained from The PEGO Thermal Power Plant in Portugal and it was classified as class F according to the ASTM-C618 [18] recommendation. The chemical composition of the fly ash used for this study is presented in Table 1. The particle size distribution of the fly ash was varied from $2 \mu \mathrm{m}$ to $59 \mu \mathrm{m}$. Fly ash was partially replaced by calcium hydroxide from LUSICAL H100. The used calcium hydroxide contains more that $99 \% \mathrm{CaO}$. The sand was employed as inert filler provided from the MIBAL, Minas de Barqueiros, S.A. Portugal. The minimum and maximum size of sand particles were distributed by $0.6 \mathrm{~mm}$ and $4.75 \mathrm{~mm}$, respectively. The detailed grain size distribution of the aggregates presented in Fig. 1a. Two types of fibres (iPLAST and iSHOTS) were used to reinforce the geopolymeric

Table 1

Major oxides in fly ash.

\begin{tabular}{lllllllll}
\hline Material & \multicolumn{1}{l}{ Oxides (wt\%) } \\
\cline { 2 - 8 } & $\mathrm{SiO}_{2}$ & $\mathrm{Al}_{2} \mathrm{O}_{3}$ & $\mathrm{Fe}_{2} \mathrm{O}_{3}$ & $\mathrm{CaO}$ & $\mathrm{MgO}$ & $\mathrm{Na}_{2} \mathrm{O}$ & $\mathrm{K}_{2} \mathrm{O}$ & $\mathrm{TiO}_{2}$ \\
\hline Fly Ash & 60.81 & 22.68 & 7.64 & 1.01 & 2.24 & 1.45 & 2.7 & 1.46 \\
\hline
\end{tabular}

mortars, which were provided from iSTRiCE, Italy (Fig. 1b). It should be noted that, as the initial lengths of the fibers were long (about $50 \mathrm{~mm}$ ), therefore, the fibers were cut to shorter lengths with an average length of $8 \mathrm{~mm}$. Using long length fibers leads to orient fibers planar, which significantly affects the flexural performance of the fiber reinforced mix compositions [48]. Thus, the fibers were cut to shorter lengths in order to assess the flexural performance of the reinforced beams containing fibers with three-dimensional orientation. The detailed characteristic of the hybrid fibers are listed in Table 2.

\subsection{Composition and production of the mortars}

Four mixtures were prepared and tested under compressive and flexural loading. The composition of the mortars is shown in Table 3. The mix proportion was composed by fly ash (90\% FA), calcium hydroxide ( $10 \% \mathrm{CH}$ several authors showed this percentage give optimal strength results [20]), alkali activator with a molarity of $12 \mathrm{M}$, an activator/binder ratio of 1.0 and sodium silicate to sodium hydroxide mass ratio of 2.5. Different hybrid fiber fractions used to reinforce the mix compositions, $0.08 \%, 0.2 \%$ or $0.8 \%$. Experimental program was carried out based on 48 specimens in two different groups, including 36 cubic specimens for compressive strength and 12 prismatic beams for flexural strength. Equal mass quantities of fibers (50\% iPLAST-50\% iSHOTS) were used to reinforce the mortars, which the fiber content of total binder mass $(\mathrm{FA}+\mathrm{CH})$. The sodium hydroxide solution was mixed with sodium silicate solution to dissolve the silica and alumina of the fly ash particles, resulting a homogenized gel lasting $1 \mathrm{~min}$; next, mixing all the solid materials together by using standard mixture following speed I (65 rpm) for $3 \mathrm{~min}$; next, addition of solution into the mixture and running the mixture for $1 \mathrm{~min}$ with speed I (65 rpm) and another $1 \mathrm{~min}$ with speed II (90 rpm). Next, the mixture was transferred to metallic moulds. The specimens were cured at laboratory conditions with temperature about $25{ }^{\circ} \mathrm{C}$ and $65 \%$ of relative humidity. After $24 \mathrm{~h}$, the specimens were demoulded and kept sealed with the plastic wrap and then left in the same curing conditions until the date of testing.

\subsection{Flexural and compressive strength testing}

Three point load bending testing was carried out at 28 days with respect to the recommendations of the European standard EN101511 [21]. Three prismatic beams with dimensions of $40 \times 40 \times 160 \mathrm{~mm}$ were cast and prepared to test. A point load was imposed to middle of beams through using operated testing frame with the capacity of $25 \mathrm{kN}$, as shown in Fig. 2. The purpose of this test was to obtain flexural load versus deflection responses for different mixtures. Three prismatic beams were tested for each mixture. A linear variable differential transformer (LVDT) used to measure mid-span deflections of beams. The test was carried out with a displacement rate of $0.6 \mathrm{~mm} / \mathrm{min}$. For each mix composition, the flexural strength values represent the average of three replicated prismatic beams. To determine the compressive strength of the mix compositions, a total number of 9 cubic specimens were considered for each mixture, which three cubic specimens were tested at ages of 7,14 , and 28 days. The test was performed with respect to the recommendations given by EN1015-11. The cubic specimens had a dimension $50 \times 50 \times 50 \mathrm{~mm}$. After casting the specimens, they were sealed with a plastic wrap and then cured at laboratory environment with relative humidity $80 \%$ and average temperature of $25{ }^{\circ} \mathrm{C}$ until testing ages. A digital standard automatic testing machine with capacity of $50 \mathrm{kN}$ was used to apply compressive load with a loading rate of $0.25 \mathrm{MPa} / \mathrm{s}$. 


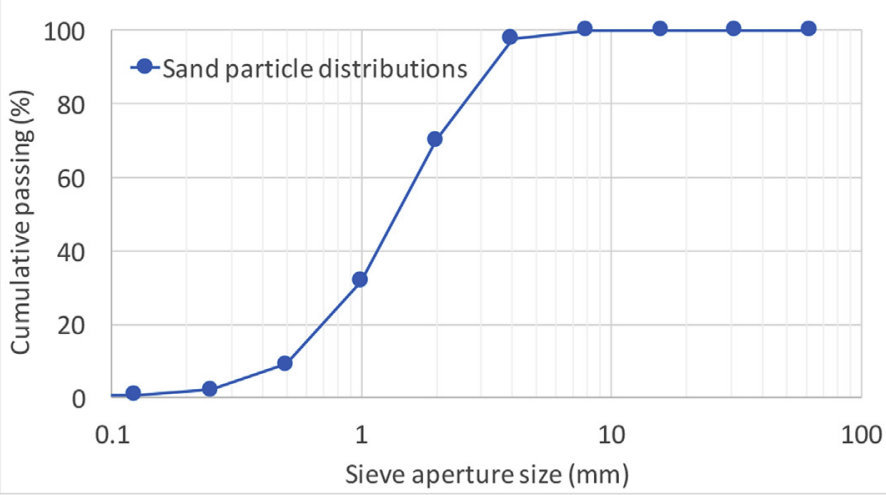

(a)

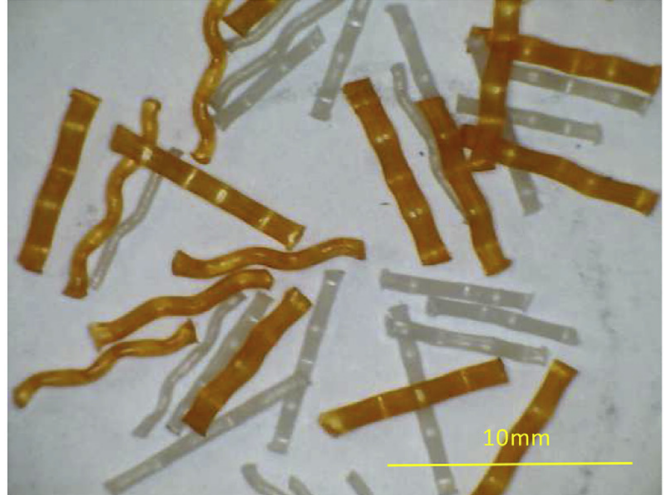

(b)

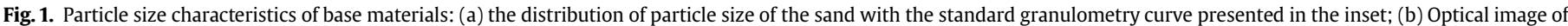

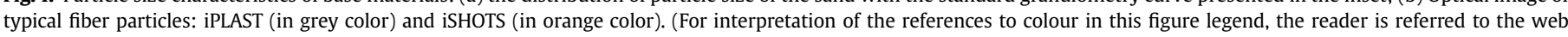
version of this article.)

Table 2

Properties of SHPF [19].

\begin{tabular}{|c|c|c|c|c|c|c|c|c|}
\hline Fibre name & Composition & Geometric shape & Colour & Initial length (mm) & Diameter (mm) & Specific weight $\left(\mathrm{kg} / \mathrm{dm}^{3}\right)$ & Ultimate strength (MPa) & Elastic module (GPa) \\
\hline iPLAST & Polymer & Monofilament/macro & Grey & 29 & 0.55 & 1.0 & 520 & 4.1 \\
\hline iSHOTS & Polymer & Monofilament/macro & Orange & 49 & 0.79 & 1.0 & 520 & 4.1 \\
\hline
\end{tabular}

Table 3

Compositions of mortars.

\begin{tabular}{|c|c|c|c|c|c|c|}
\hline \multirow[t]{2}{*}{ Sample name } & \multicolumn{6}{|c|}{ Materials $\left(\mathrm{kg} / \mathrm{m}^{3}\right)^{\mathrm{a}}$} \\
\hline & FA & $\mathrm{CH}$ & SA & SS & $\mathrm{SH}$ & $\mathrm{HF}$ \\
\hline 90FA_10CH_12M_2.5S/H_1.0A/B_0.0HF & 415.8 & 46.2 & 1385.9 & 329.5 & 132.4 & 0 \\
\hline 90FA_10CH_12M_2.5S/H_1.0A/B_0.08HF & 415.5 & 46.1 & 1385.1 & 329.3 & 132.3 & 0.6 \\
\hline 90FA_10CH_12M_2.5S/H_1.0A/B_0.2HF & 415.1 & 46.1 & 1383.9 & 329.1 & 132.2 & 1.4 \\
\hline 90FA_10CH_12M_2.5S/H_1.0A/B_0.8HF & 413.4 & 45.9 & 1378.1 & 327.7 & 131.7 & 5.7 \\
\hline
\end{tabular}

${ }^{\text {a }}$ FA: stands for the fly ash; $\mathrm{CH}$ : calcium hydroxide; SA: sand; SS: sodium silicate; SH: sodium hydroxide; and HF: hybrid fibers.

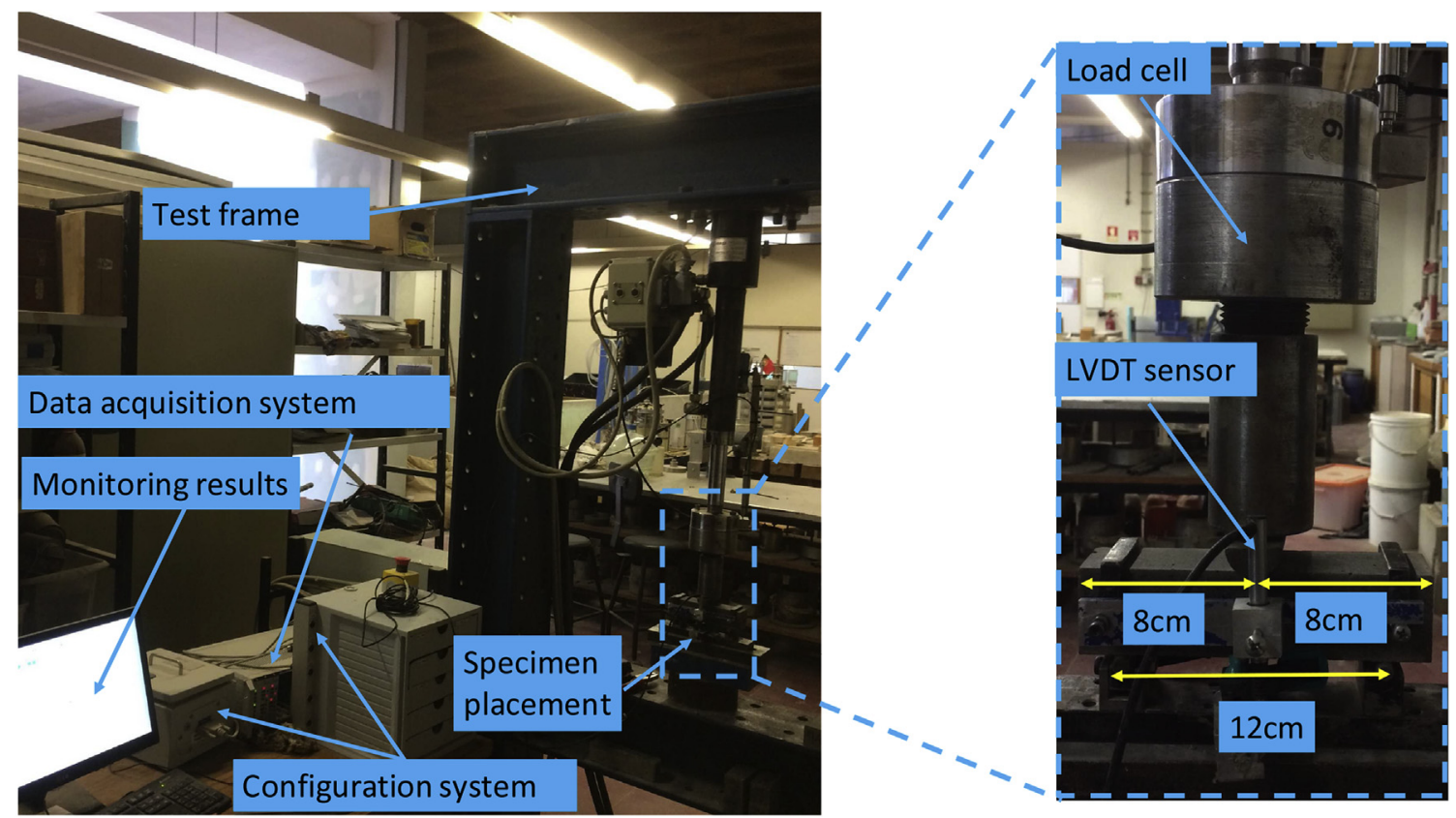

Fig. 2. Adopted test setup for the execution of the flexural strength. 


\section{Results and discussion}

\subsection{Compressive strength}

The results of the compressive strength according to curing age are shown in Fig. 3. The compressive strength of the several geopolymeric mixtures at 7 days reached to $75 \%$ compressive strength of mix compositions at 28 days. The addition of SHPF seems not influence the 28 days compressive strength. However, a slight compressive reduction is noticed for 7 and 14 curing days. This means that a possible increase in porosity du to fibre addition is overcome at later curing ages when the binder has hardened enough so the crack arrest effect of fibres become evident. This compressive strength reduction was also noticed by other authors working with fibre reinforced geopolymers [16,22]. Other authors [23] reported a decrease in the compressive strength in the mix compositions containing a fibre content above $0.5 \%$. The results also show that adding $0.8 \%$ hybrid fiber has the highest impact on the crack arresting capacity of fibers at early and final ages. Concerning the results, it was found that addition of hybrid fibres causes decreases on the compressive strength of the mix compositions up to $5.7 \%$ in the reinforced specimens with $0.2 \%$ hybrid fibers.

\subsection{Flexural strength}

The result of flexural load versus mid span deflection response was depicted in Fig. 4. By increasing fiber content, the maximum flexural load and the ultimate deflection corresponding to the maximum flexural load of specimens increased. Using hybrid fibers provides the synergetic benefits of fibers of different properties in terms of assuring effective crack control at different stage of the crack propagation $[23,24]$. Similar benefits were also reported by authors through using cement-based composites in Refs. [25,26]. Fibers bridging micro-cracks contribute to the formation of diffuse crack patterns, since they offer resistance to the coalescence of the earlier micro-cracks into macro-cracks. Short discrete fibers are more effective than long discrete fibers in stopping microcracks from growing into the localized crack. Thus, adding short discrete fibers results in increasing the flexural strength due to fiber bridging action. The roughness of fiber surface improves the bond at interface of fiber/matrix, which affect the fiber bridging action. Regarding the results, reinforced specimens behaved brittle under imposed the flexural load. By increasing hybrid fiber content above $0.8 \%$, it is possible to record deflection-hardening behavior. It is worth stating that adding fibers had no significant effect on the flexural stiffness of the beams. Equation (1) was used to compute the flexural strength $\left(\sigma_{\mathrm{f}}\right)$ of specimens under three point bending (TPB) test:

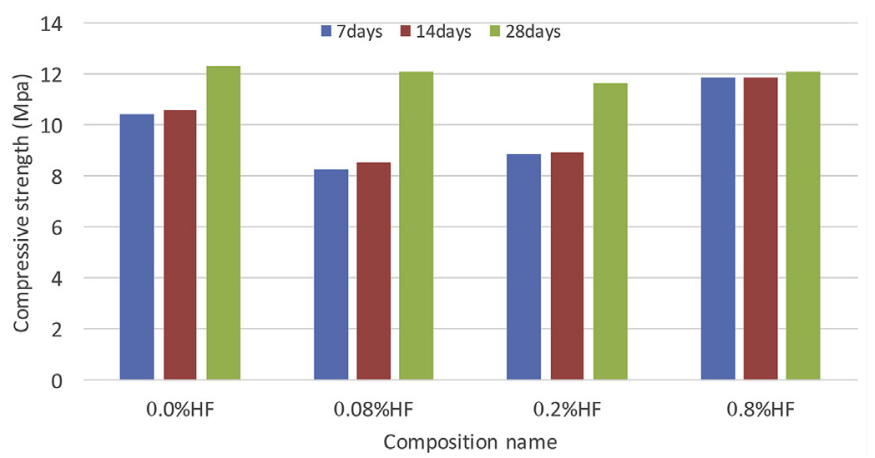

Fig. 3. Compressive strength at 7, 14 and 28 days.

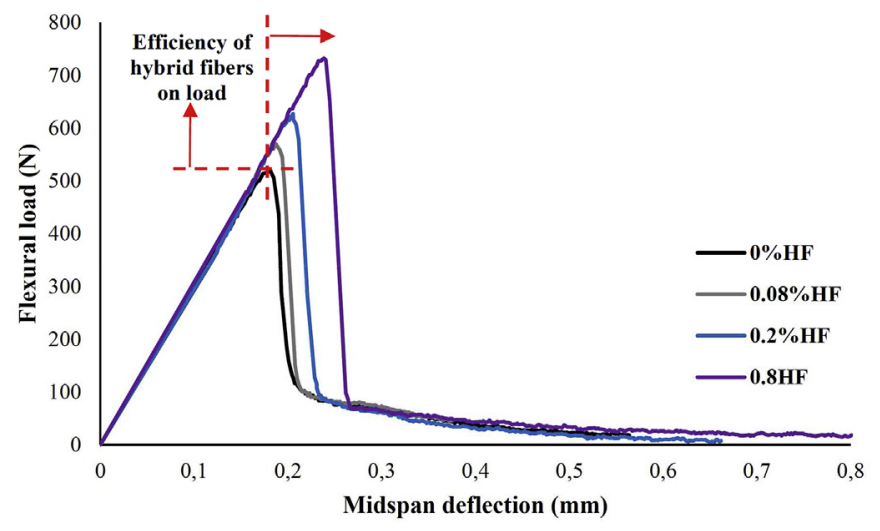

Fig. 4. Flexural load vs. midspan deflection response of tested beams according to fibre content.

$\sigma_{f}=\frac{3 F L}{2 b h^{2}}$

where, $\mathrm{F}$ is the maximum flexural load, $\mathrm{L}$ is span length, $\mathrm{b}$ and $\mathrm{h}$ are width (equal to $40 \mathrm{~mm}$ ) and height (equal to $40 \mathrm{~mm}$ ) of beams, respectively.

The effects of adding different fiber fractions on the flexural strength and ultimate deflection were illustrated in Fig. 5a and b. By increasing fiber content, bridging action of fibres offers more resistance to crack opening in the specimens with transferring stress from hybrid fibres to the matrix regard to interfacial shear strength. Thus, increasing fiber fractions increased both flexural strength and ultimate deflection. With respect to the results, the maximum increase of the flexural strength (about 40\%) and ultimate deflection (about 30\%) were recorded in the reinforced beam with $0.8 \%$ hybrid fibers. Moreover, the flexural strength and ultimate deflection were correlated to the fiber fraction linearly through using linear regression. With respect to the developed equations in Fig. 5c, the flexural strength and ultimate deflection could be correlated to the fiber fraction with high coefficient of determination $\left(\mathrm{R}^{2}>0.92\right)$. Furthermore, it was revealed that addition of fibers had greater impact on increasing the flexural strength than ultimate deflection.

\subsection{Flexural toughness}

The flexural toughness of the beams was assessed by measuring the area under flexural load - deflection response up to L/150 [27,53]. Fig. 6 indicates the absorbed energy of different mix compositions. As shown, increasing fiber content increased the flexural toughness, when compared to the plain geopolymer concrete. Regarding the results, increasing the fiber content above $0.2 \%$ has great impact on the absorbed energy so that the maximum absorbed energy was recorded about $140 \mathrm{~N} \mathrm{~mm}$, which was about $60 \%$ more than the absorbed energy in the beams made with the plain geopolymer concrete. Various studies have been reported the efficiency of fibers on increasing the absorbed energy of the reinforced mixtures due to bridging action of fibers $[28,29]$. After characterizing mechanical properties of fiber reinforced geopolymeric mortars in the first stage of this paper, it was required to assess the efficiency of hybrid fibers on the flexural performance of the reinforced beams with longer length. Therefore, in the second stage of this paper, the flexural performance of beams was evaluated by using numerical simulations. Regarding this aim, the Finite Element (FE) models were developed through using an inverse analysis. 


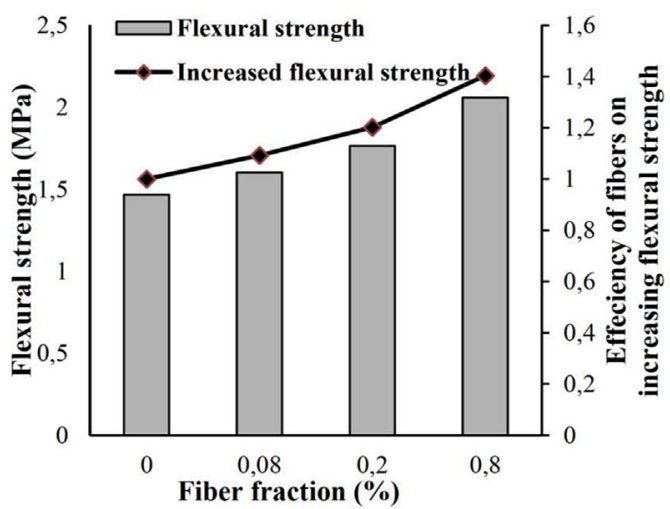

a)

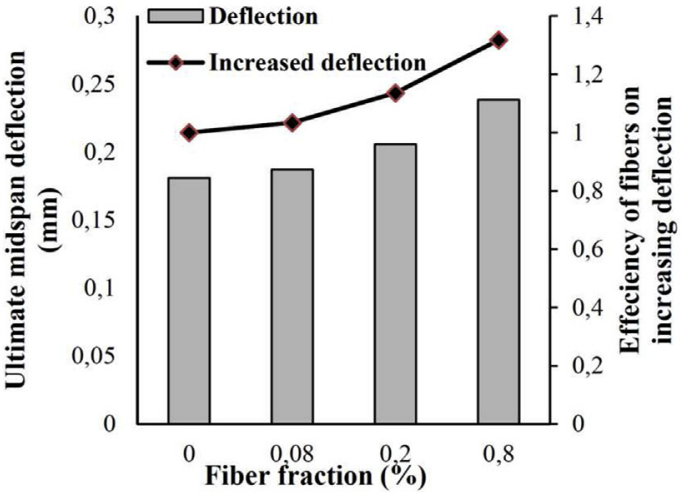

b)

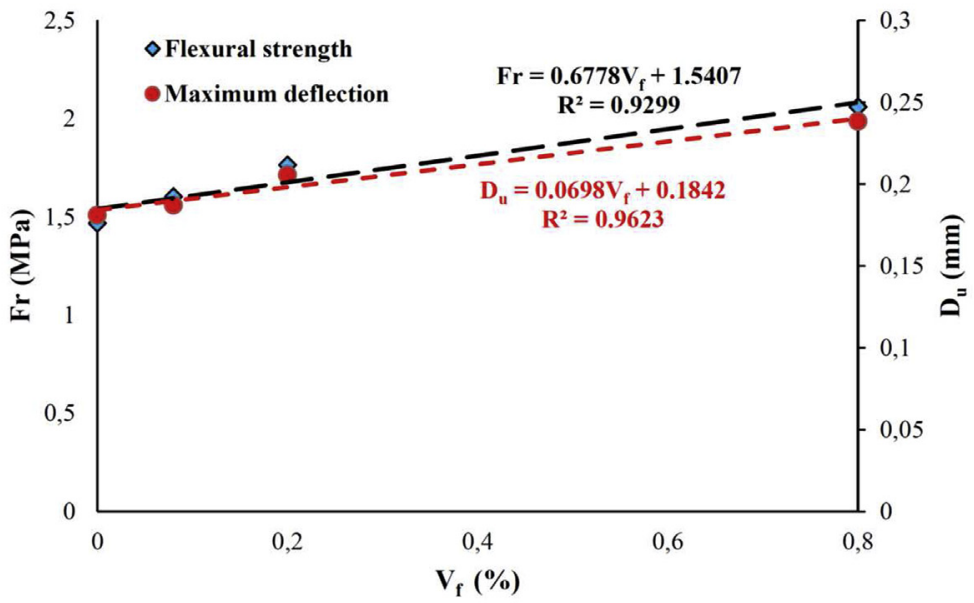

c)

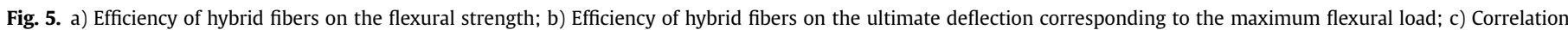
between the flexural strength and deflection with fiber fraction. Where, $\mathrm{Vf}$ is fiber fraction, Du is ultimate deflection and Fr is the flexural strength.

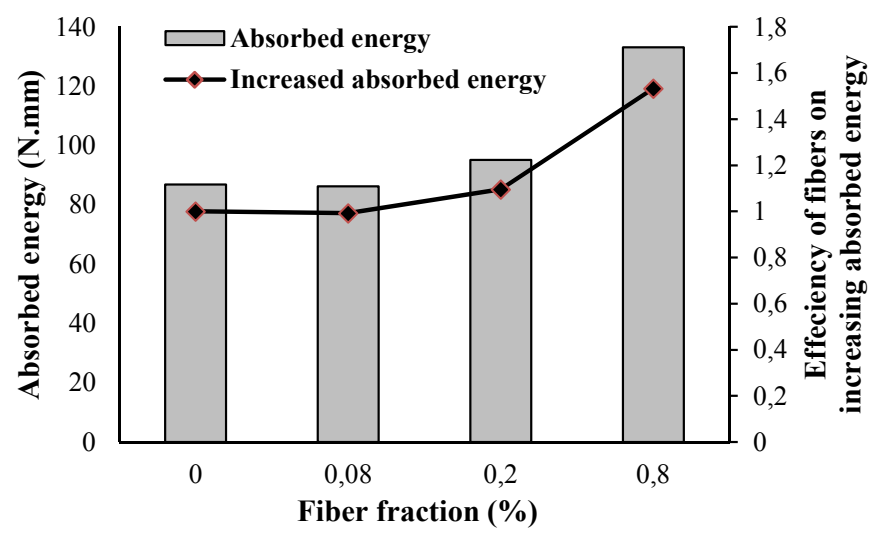

Fig. 6. Flexural toughness according to SHPF content.

\section{Numerical simulation}

The FEMIX software, a Finite Element Method (FEM) based software program that is able to simulate nonlinear behavior of several types of materials, was employed at this stage of the study. The software was developed at Minho University. The multidirectional fixed smeared crack constitutive model was used to simulate the crack initiation and propagation in the fiber reinforced geopolymer concrete in the FEMIX software version 4.0. The simulation process is briefly described below. In order to analyze the beams with Finite Element (FE) models, they were considered as plane stress problems. The explanation of the formulation of the multi-directional fixed smeared crack constitutive model is related to the case of cracked concrete, at the domain of an integration point (IP). It is worth stating that continuum models like microplane constitutive law can be used to simulate the crack propagation in concrete. Regarding the numerical simulations in Refs. [49,50], it was demonstrated that the microplane model has high capacity in simulating behavior of concrete under dominant tension, compression and complex non-proportional loading histories. This model has been successfully used in the simulation of concrete columns confined with FRP materials [51,52]. In the present paper, smeared crack constitutive models were used, because conceptually this model is more appropriate than discrete crack models in the simulation of crack propagation in fiber reinforced cement concrete, mainly, in those with a high number of redundant supports.

According to the adopted constitutive law for plane stress finite element, stress and strain are related to each other by:

$\Delta \sigma=D^{\operatorname{Crcon}} \Delta \varepsilon$

where $\Delta \sigma=\left\{\Delta \sigma_{1}, \Delta \sigma_{2}, \Delta \tau_{12}\right\}^{T}$ and $\Delta \varepsilon=\left\{\Delta \varepsilon_{1}, \Delta \varepsilon_{2}, \Delta \gamma_{12}\right\}^{T}$ are the components of stress and strain vectors, respectively. By decomposing the total strain in (2) into elastic and cracked concrete parts, i.e. $\Delta \varepsilon=\Delta \varepsilon^{\text {ela }}+\Delta \varepsilon^{\text {cra }}$, $D^{\text {Concra }}$ will be determined using [30]: 
$D^{C r c o}=D^{C o}-D^{C o}\left[T^{C r}\right]^{T}\left(D^{c r}+T^{C r} D^{C o}\left[T^{C r}\right]^{T}\right)^{-1} T^{c r} D^{C o}$

where $\mathrm{D}^{\mathrm{Con}}$ is the constitutive matrix of concrete assumed to have a linear behavior:

$D^{C o}=\frac{E_{C}}{1-v_{C}^{2}}\left[\begin{array}{ccc}1 & \nu_{c} & 0 \\ v_{c} & 1 & 0 \\ 0 & 0 & \frac{1-v_{c}}{2}\end{array}\right]$

which $\mathrm{E}_{\mathrm{c}}$ and $v_{\mathrm{C}}$ are elasticity modulus and Poisson's ratio of concrete, respectively. $\mathrm{T}^{\mathrm{Cr}}$ in (3) is the transform matrix of stress components from the coordinate system of element to local crack coordinate system. If $\mathrm{n}$ is the number of cracks, $\mathrm{T}^{\mathrm{Cr}}$ will be defined as:

$T^{C r}=\left[T_{1}^{C r} \ldots T_{i}^{C r} \ldots T_{n}^{C r}\right]^{T}$

where, the crack orientation matrix is given by:

$T_{i}^{C r}=\left[\begin{array}{ccc}\cos ^{2} \theta & \sin ^{2} \theta & 2 \sin \theta \cos \theta \\ -\sin \theta \cos \theta & \sin \theta \cos \theta & \cos ^{2} \theta-\sin ^{2} \theta\end{array}\right]$

and $\theta$ is defined as the angle between the $\mathrm{x}_{1}$ axis and the vector orthogonal to the plane of the $i_{\text {th }}$ crack. Furthermore, $D^{\mathrm{Co}}$ in (3) is defined as a matrix that includes the constitutive law of the $n$ cracks:

$$
\begin{array}{ccccc}
D_{1}^{C r} & \ldots & 0 & \ldots & 0 \\
\ldots & \ldots & \ldots & \ldots & \ldots \\
0 & \ldots & D i^{C r} & \ldots & \ldots \\
\ldots & \ldots & \ldots & \ldots & \ldots \\
0 & \ldots & 0 & \ldots & D n^{C r}
\end{array}
$$

In the above equation, $D_{i}^{C r}$ is the crack constitutive matrix of the ith crack, which is defined as:

$D^{C r}=\left[\begin{array}{cc}D_{I, i}^{C r} & 0 \\ 0 & D_{I I, i}^{C r}\end{array}\right]$

$D_{I, i}^{c r}=-k_{i} \frac{l_{c r} f^{2}{ }_{c t}}{G_{f}}$

$k_{1}=\frac{\left(1-\alpha_{1}\right)\left(\xi_{1}+\alpha_{1} \xi_{2}-\alpha_{2} \xi_{1}+\alpha_{2}\right)}{2 \xi_{1}}$

$k_{2}=\frac{\left(\alpha_{1}-\alpha_{2}\right)\left(\xi_{1}+\alpha_{1} \xi_{2}-\alpha_{2} \xi_{1}+\alpha_{2}\right)}{2\left(\xi_{2}-\xi_{1}\right)}$

$k_{3}=\frac{\alpha_{2}\left(\xi_{1}+\alpha_{1} \xi_{2}-\alpha_{2} \xi_{1}+\alpha_{2}\right)}{2\left(1-\xi_{1}\right)}$

where, $D_{I, i}^{C r}$ and $D_{I I, i}^{C r}$ are the moduli corresponding to the fracture mode I (normal) and fracture mode II (shear) of the ith crack, respectively. In this numerical approach, a new crack forms in an integration point (IP) when the angle between the new crack and the already existing cracks exceeds a certain threshold angle (This angle is selected between 30 and $60^{\circ}$ according to [30]). The crack opening propagation was simulated using the trilinear diagram, which is indicated in Fig. 7. Normalized stresses $\left(\alpha_{1}\right.$ and $\left.\alpha_{2}\right)$ and strains $\left(\xi_{1}\right.$ and $\left.\xi_{2}\right)$ were defined and used for transposition points

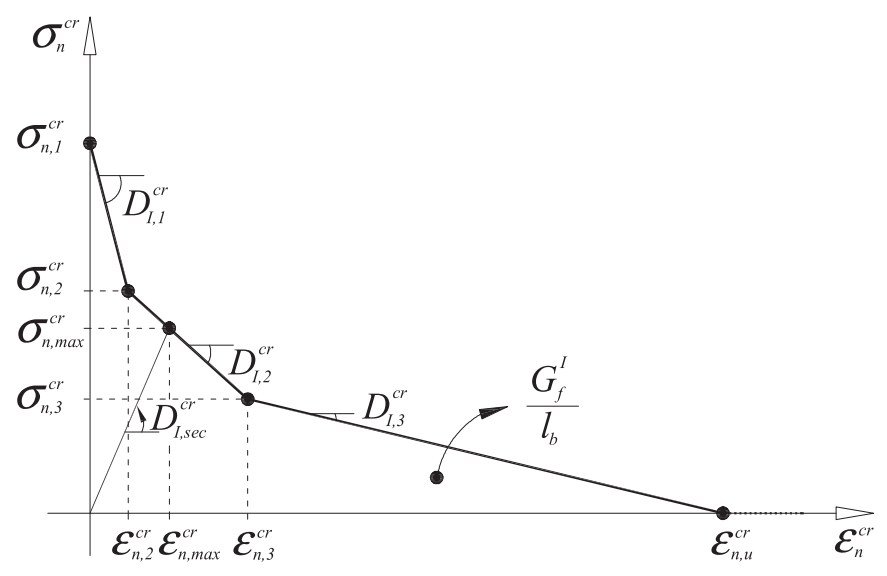

Fig. 7. Trilinear stress-strain diagram in simulation of the fracture mode I crack propagation $\left(\sigma_{n, 1}^{c r}=f_{c t}, \sigma_{n, 2}^{c r}=\alpha_{1} \sigma_{n, 1}^{c r}, \sigma_{n, 3}^{c r}=\alpha_{2} \sigma_{n, 1}^{c r}, \varepsilon_{n, 2}^{c r}=\xi_{1} \varepsilon_{n, u}^{c r}, \varepsilon_{n, 3}^{c r}=\xi_{2} \varepsilon_{n, u}^{c r}\right)$.

between the linear segments of the diagram. The ultimate crack strain $\left(\varepsilon_{n}^{C r}\right)$ is a function of the fracture energy, tensile strength $\left(\sigma_{t}^{c r}\right)$, crack bandwidth $\left(\mathrm{l}_{\mathrm{Cr}}\right)$ and normalized strains and stresses. Thus, the ultimate crack strain is given by Ref. [31]:

$\varepsilon_{n}^{C r}=\frac{2}{\xi_{1}+\alpha_{1} \xi_{2}-\alpha_{2} \xi_{1}+\alpha_{2}}\left(\frac{G_{f}}{l_{c r} \sigma_{t}^{C r}}\right)$

and the fracture mode II modulus, $\mathrm{D}_{\mathrm{II}}^{\mathrm{Cr}}$, is defined by Ref. [34]:

$D_{I I}^{C r}=\frac{\kappa}{1-\kappa} G_{C}$

where, $G_{c}$ is the elastic concrete shear modulus and $\kappa$ is the shear retention factor. The parameter $\kappa$ is considered as a function of the current crack normal strain $\left(\varepsilon^{\mathrm{Cr}}\right)$ and ultimate crack normal strain $\left(\varepsilon_{\mathrm{n}}^{\mathrm{Cr}}\right)[34]:$

$\kappa=\left(1-\frac{\varepsilon^{C r}}{\varepsilon_{n}^{C r}}\right)^{P_{1}}$

If $\mathrm{P}_{1}=1, \kappa$ will decrease linearly as $\varepsilon_{n}^{\mathrm{Cr}}$ increases. Higher values of the exponent results in more decrease in $\kappa$ [31]. Regarding fracture mode II, the total and the incremental approaches, depicted in Fig. 8, and more details explained in Ref. [31], are available in FEMIX, but in the numerical simulations implemented the total approach was adopted due to its better performance. The beams were modelled by a mesh of 8 node serendipity plane stress finite elements. The Gauss-Legendre integration scheme with $2 \times 2$ integration points was used for all elements. The values adopted for simulating the behavior of the fiber reinforced geopolymeric mortar beams are listed in Table 4.

The adopted multi-directional fixed smeared crack constitutive model in this study can be used in the analysis of either plain concrete or reinforced concrete (RC) structures. In the plain concrete structures, tensile stresses are transmitted across the cracks during the initiation of cracks for small crack widths, which this is designated as tension softening. The relevance of mesh dependency in the FEM analyses for the plain concrete is well-known and widely discussed in the literature [37-41]. Regarding the results, it was observed that the effects of the FEM size could be reduced if the tensile stress-strain laws for the plain concrete define as a function of both fracture energy $\left(\mathrm{G}_{f}\right)$ and the crack bandwidth $\left(l_{b}\right)$. It is worth stating that using this approach can be achieved very satisfactory results when the size of meshes is relatively small. Although, using large size of FEM meshes results in recording 


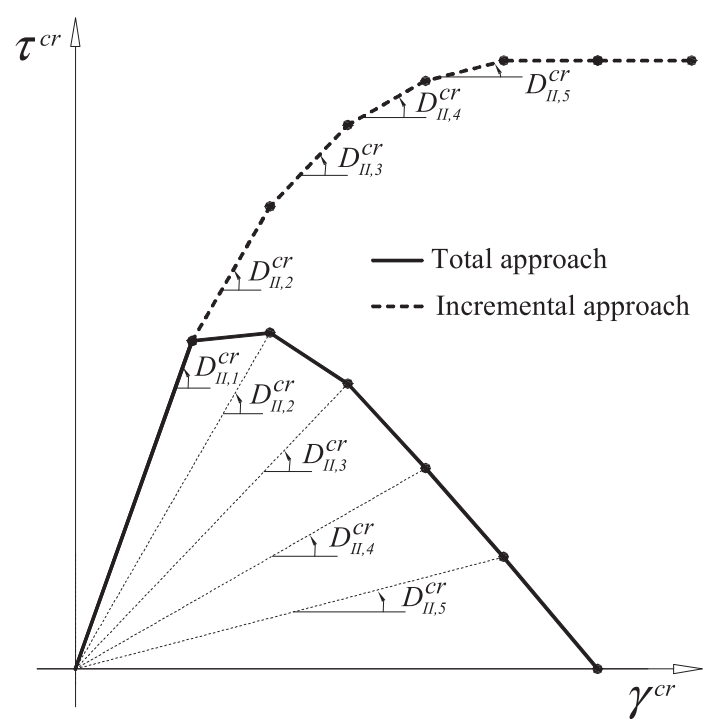

Fig. 8. Relation between crack shear stress and crack shear strain for the incremental and total approaches. significant differences between the experimental data and numerical results.

Since mechanical response for each crack is functioned by the tension stiffening effects, different approaches should be employed to minimize the effects of mesh dependency in the RC elements due to crack localization [42].

Recently, some continuous FEM models such as random lattice model were proposed to avoid mesh dependence in fiberreinforced polymers (FRPs). This discrete model was successfully used in Ref. [43] to correctly capture the crack paths and maintaining a substantial independence on the mesh in FRPs.

In this study to minimize the effects of mesh dependence, the tensile stress-strain laws for plain concrete was considered as a function of both the fracture energy and the crack bandwidth, as depicted in Fig. 7. Moreover, a sensitivity analysis was conducted to obtain a mesh refinement, which does not affect the accuracy of the simulations. This analysis was executed by refining the mesh under linear elastic behavior only to achieve stabilization in the results. Regarding this analysis, sixty-four elements were used to simulate the fiber-reinforced geopolymeric beams. The size of the concrete elements depends on the geometry of beams, therefore, regarding the prismatic shape of beams the size of the concrete elements was

Table 4

Properties adopted to simulate the nonlinear behavior of the fiber reinforced geopolymer beams.

\begin{tabular}{|c|c|}
\hline Poisson's ratio [32] & $v_{c}=0.15$ \\
\hline Initial Young's modulus [33] & $E_{c}=18420 \mathrm{MPa}$ \\
\hline Maximum number of cracks per integration point [20] & 2 \\
\hline Parameter defining the mode I fracture energy available to the new crack [30] & 2 \\
\hline Parameter defining the shear retention evolution $\left(\mathrm{p}_{1}\right)[31]$ & 2 \\
\hline Crack band-width, $l_{c r}[30]$ & Square root of the area of the Gauss-Legendre integration point $(\sqrt{ } \mathrm{Ai})$ \\
\hline
\end{tabular}

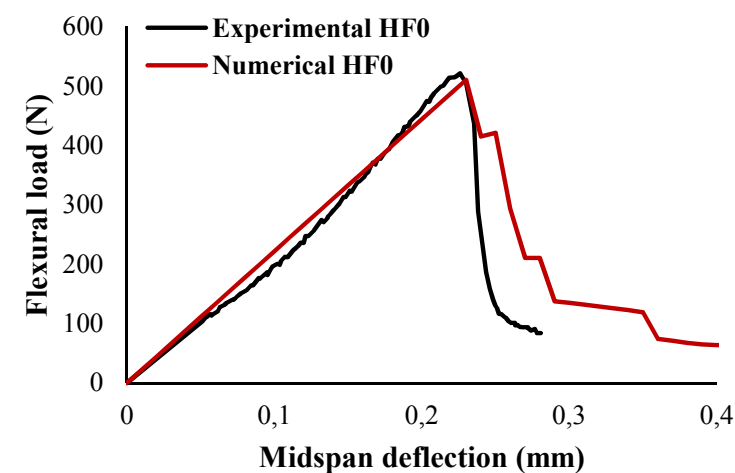

a) HFO

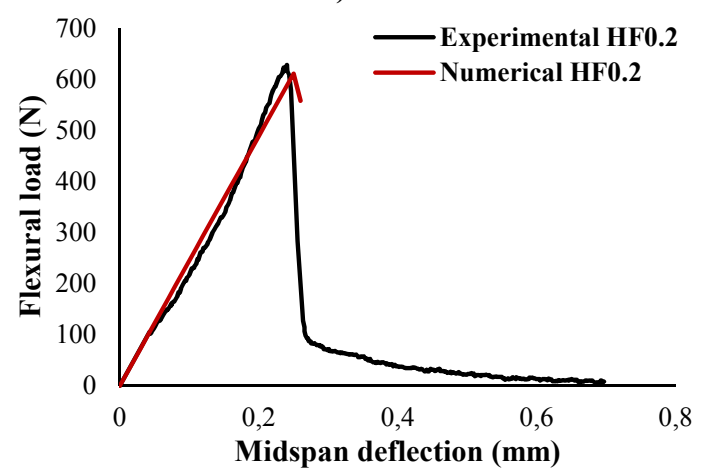

c) HF0.2

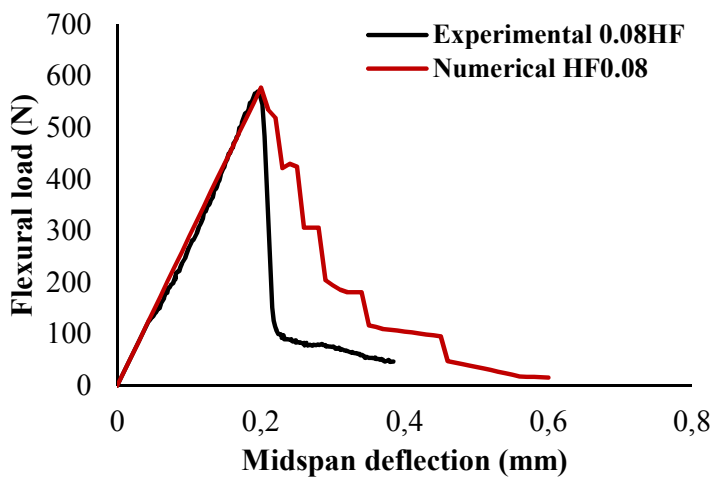

b) HF0.08

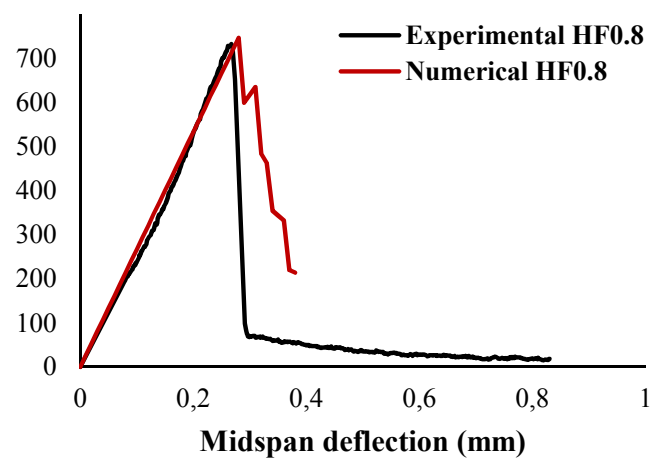

d) HF0.8

Fig. 9. Experimental and numerical simulations of the reinforced beams. 
considered $10 \times 10 \mathrm{~mm}$.

The boundary conditions used in the numerical simulations are illustrated in Fig. 10a. The displacement in the Z-axis was restricted at both end sides of beams, while the displacement in direction of Y-axis was restricted at the left side, as depicted in Fig. 10a. The total applied deflection was divided into a series of deflection increments. Newton method iterations provided convergence, within tolerance limits, at the end of each deflection increment. The stability failure was selected as a failure criterion. Stability failure was observed whenever an extremely large, sudden displacement occurred.

Since no available experimental results exist to characterize the parameters of fracture mode I, to obtain the fracture energy (the area under tensile stress-strain response), tensile strength, ratios $\alpha_{1}, \alpha_{2}, \xi_{1}, \xi_{2}$, that define the tri-linear stress-strain softening diagram (see Fig. 7), an inverse analysis using the force-deflection relationships was performed through using fitting the experimental results as best as possible. The inverse analysis assessed these parameters values, leading to the minimization of the ratio between the area limited by the experimental and the numerical curves (in absolute values) and the area underneath the experimental curve. The numerical results obtained, where the specimen, the loading and the support conditions were simulated in agreement with the experimental test setup. On the other hand, the values reported in Table 5 were based on minimizing the differences between the numerical and experimental results (the force-deflection relationship). Fig. 9 depicts the results obtained from numerical simulation of the tested beams. The numerical results were well-fitted to the experimental results, indicating an acceptable agreement between experimental and numerical results. The parameters of fracture mode I including the crack strength, fracture energy, normalized stresses, and strains were calculated according to the inverse analysis and listed in Table 5. Pereira et al. [35] indicated that fracture mode I propagation of fiber reinforced concrete can be

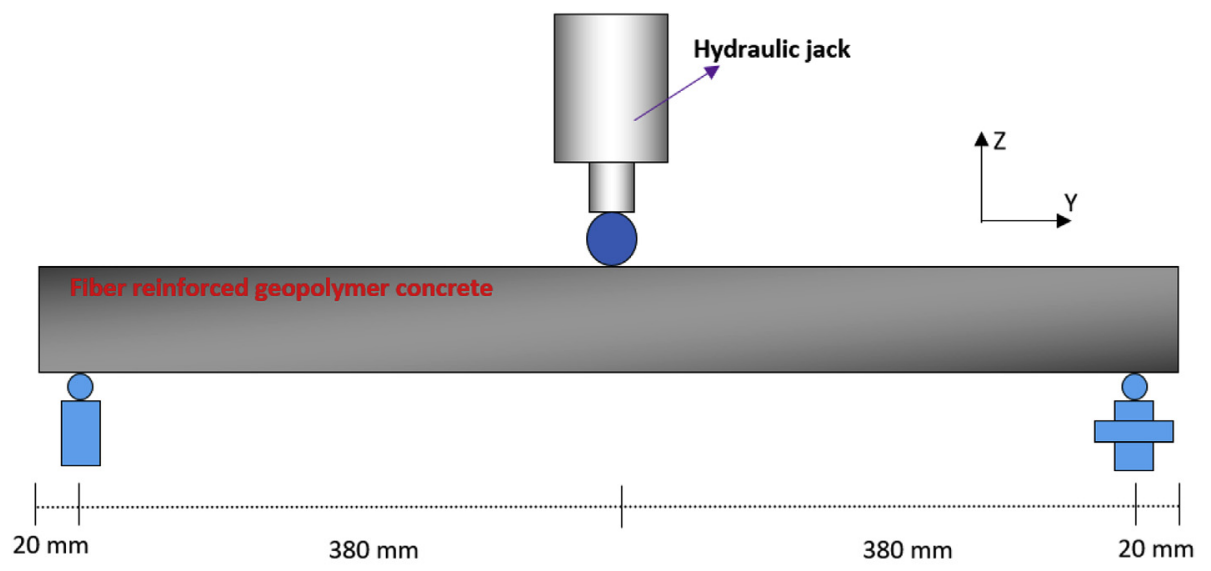

a)

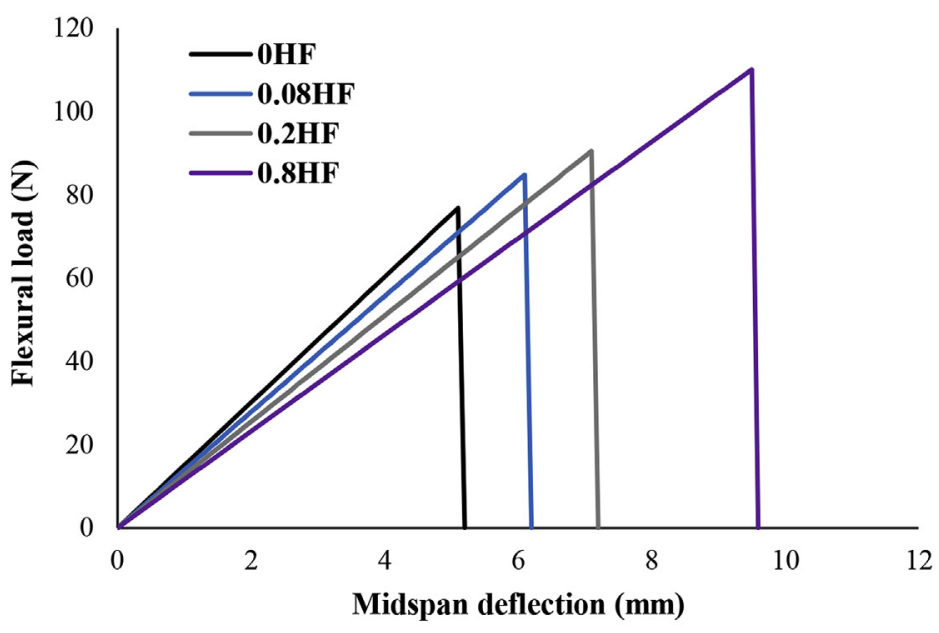

b)

Fig. 10. a) Adopted test setup for beam with $800 \mathrm{~mm}$ length; b) Obtained results for numerical models simulated with $800 \mathrm{~mm}$ length

Table 5

Results obtained from execution of inverse analysis.

\begin{tabular}{|c|c|c|c|c|c|c|}
\hline Specimen designation & $\alpha_{1}$ & $\alpha_{2}$ & $\xi_{1}$ & $\xi_{2}$ & Fracture energy $(\mathrm{N} / \mathrm{mm})$ & Tensile strength (MPa) \\
\hline OHF & 0.20 & 0.40 & 0.21 & 0.50 & 0.030 & 1.21 \\
\hline $0.08 \mathrm{HF}$ & 0.20 & 0.40 & 0.21 & 0.50 & 0.040 & 1.33 \\
\hline $0.2 \mathrm{HF}$ & 0.20 & 0.40 & 0.21 & 0.50 & 0.045 & 1.43 \\
\hline $0.8 \mathrm{HF}$ & 0.20 & 0.40 & 0.21 & 0.50 & 0.060 & 1.72 \\
\hline
\end{tabular}


Table 6

Comparison of the numerical and experimental results.

\begin{tabular}{lllll}
\hline & OHF & $0.08 \mathrm{HF}$ & $0.2 \mathrm{HF}$ & $0.8 \mathrm{HF}$ \\
\hline$F_{\text {Exp }}$ & 1.02 & 0.98 & 1.02 & 0.98 \\
$F_{\text {Num }}$ & 0.98 & 0.97 & 0.96 & 0.95 \\
$\frac{\left(D_{u}\right)_{\text {Exp }}}{\left(D_{u}\right)_{\text {Num }}}$ & 1.04 & 1.01 & 1.06 & 1.02 \\
$\frac{(E)_{\text {Exp }}}{(E I)_{\text {Num }}}$ & & & &
\end{tabular}

where, $F$ is the maximum flexural load, $D_{u}$ is deflection corresponding to the maximum flexural load and EI is the stiffness of beams. The flexural stiffness is recorded as the slope of force-deflection response in the linear phase.

simulated by the trilinear diagram represented in Fig. 7, whose parameters of mode I fracture energy, including the ultimate crack strain, the fracture energy, the tensile strength, and the crack band width can be obtained through execution of an inverse analysis by calibrating the numerical results in terms of force-deflection response registered in the experimental tests [35]. Concerning the numerical results, increasing the fiber fraction increased consistently the tensile performance of beams so that addition of $0.8 \%$ increased about two times fracture energy and about 50\% tensile strength, when compared to the beam made with plain geopolymer. Table 6 presents a comparison between experimental and numerical results to investigate the accuracy of the developed numerical models. Regarding the results obtained, the maximum error between numerical and experimental results in terms of the maximum force, deflection corresponding to the maximum force, and flexural stiffness were $2 \%, 5 \%, 4 \%$, respectively. Providing a shear span to depth ratio equal or greater than 2.5 leads to attain flexural failure in the beams [36], therefore, the length of beams increased from $160 \mathrm{~mm}$ to $800 \mathrm{~mm}$. In the second stage of numerical analysis, the developed numerical models for beams with length of $160 \mathrm{~mm}$ were used to simulate the beams with length of $800 \mathrm{~mm}$. This section aimed to investigate the effects of hybrid short fibers on the flexural performance of beams considering a shear span to depth ratio greater than 2.5. The adopted test setup for beams with length of $800 \mathrm{~mm}$ is indicated in Fig. 10a. Three hundred and twenty elements were used to simulate beams with length of $800 \mathrm{~mm}$. Similar to simulated beams with length of $180 \mathrm{~mm}$, boundary conditions and failure criteria were considered to model beams with length of $800 \mathrm{~mm}$. The point load was imposed to the middle of beams. The results obtained from the modeled beams with length of $800 \mathrm{~mm}$ are depicted in Fig. 10b. Regarding the results, increasing length reduced the maximum flexural load and increased the ultimate deflection corresponding the maximum load, when compared to beams with shorter span. Consistently, increasing the fiber content enhanced the flexural performance of beams due to the fiber bridging action so that the ultimate deflection for the fiber reinforced geopolymer mortars with $0.8 \% \mathrm{HF}$ increased about 2 times with respect to the beam made with the reference geopolymers. Furthermore, the maximum flexural load was increased about $50 \%$ for the beam reinforced with $0.8 \% \mathrm{HF}$ in compare to beam made with the reference geopolymers. For the beams with length of $800 \mathrm{~mm}$, the maximum flexural strength was obtained about $2 \mathrm{MPa}$ in the reinforced specimen with $0.8 \% \mathrm{HF}$, which is $50 \%$ higher than the flexural strength of beam made with the reference geopolymeric mixtures, as indicated in Fig. 11.

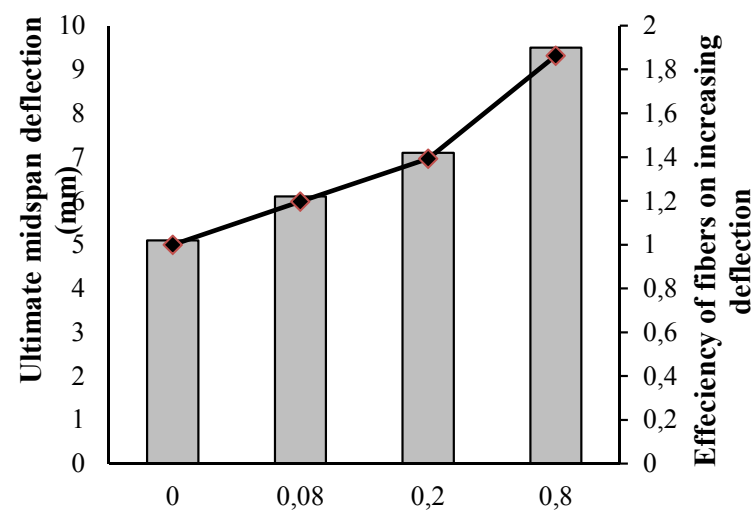

Fiber fraction $(\%)$

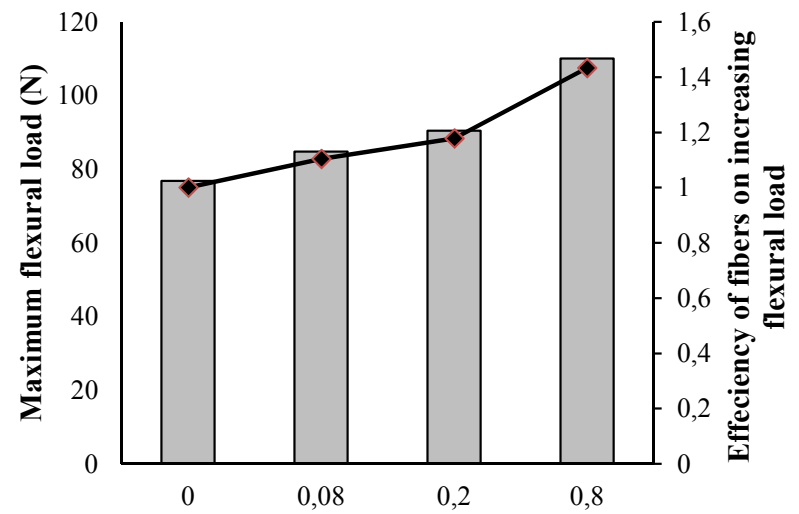

Fiber fraction $(\%)$

a)

b)

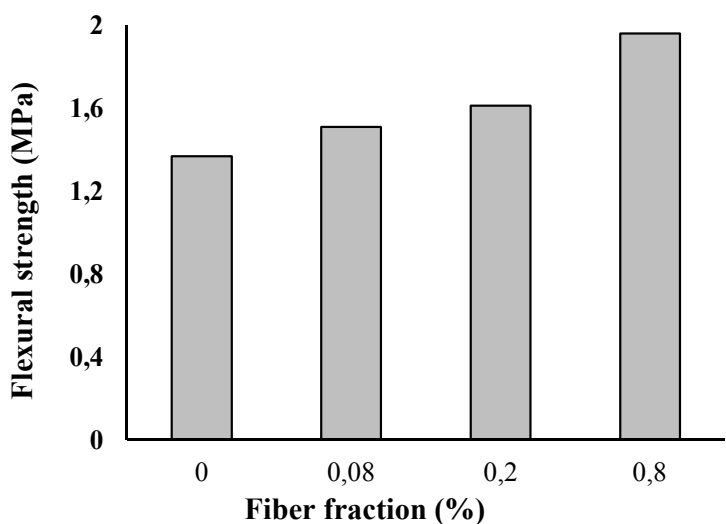

c)

Fig. 11. Effects of fibers on: a) ultimate midspan deflection; b) maximum flexural load; c) flexural strength. 


\section{Conclusion}

This work aimed to investigate the effects of using SHPF on the hardened properties of fly ash based geopolymeric mortars. The nfluence of different fiber content on the hardened state properties of geopolymeric mortars were assessed in terms of flexural and compressive strengths. Afterwards, the flexural performance of fiber reinforced fly ash based geopolymeric mortars was assessed by using numerical simulations. Based on the collected experimental and numerical results the following remarks could be highlighted:

1. SHPF improved the flexural performance, while reducing the compressive strength and flexural stiffness of geopolymeric mortars.

2. Generally, the compressive strength at early ages reached to $0.75 \%$ the compressive strength of mixtures at 28 days.

3. The adopted multi-directional fix smeared crack constitutive model well-captured the flexural performance of the tested fly ash geopolymeric mortar beams.

4. Addition of $0.8 \%$ hybrid fibers increased about two times fracture energy and about 50\% tensile strength, when compared to the beam made with the plain geopolymeric mortars.

5. For the reinforced beams with short length, due to adding hybrid fibers, higher efficiency was recorded for the flexural load than ultimate deflection. While, increasing the length of the reinforced beams with hybrid fibers resulted in observing higher efficiency for the ultimate deflection than the flexural load.

\section{Acknowledgments}

The authors would like to acknowledge the financial support of the Foundation for Science and Technology in the frame of project IF/00706/2014-UM.2.15.

\section{References}

[1] Provis JL. Geopolymers and other alkali activated materials: why, how, and what? Mater Struct 2014;47:11-25.

[2] van Deventer JSJ, Provis JL, Duxson P. Technical and commercial progress in the adoption of geopolymer cement. Miner Eng 2012;29:89-104.

[3] Pacheco-Torgal F. Introduction. In: Pacheco-Torgal F, Labrincha J, Palomo A Leonelli C, Chindaprasirt P, editors. Handbook of alkali-activated cements, mortars and concretes. Cambridge, UK: WoddHead Publishing; 2014. p. 1-16.

[4] Van Deventer J, Provis J, Duxson P, Brice D. Chemical research and climate change as drivers in the commercial adoption of alkali activated materials. Waste Biomass Valor 2010;1:145-55.

[5] Payá J, Monzó J, Borrachero MV, Tashima MM. Reuse of aluminosilicate industrial waste materials in the production of alkali-activated concrete binders. In: Pacheco-Torgal F, Labrincha J, Palomo A, Leonelli C, Chindaprasirt P, editors. Handbook of alkali-activated cements, mortars and concretes. Cambridge, UK: WoddHead Publishing; 2014. p. 487-518.

[6] Chindaprasirt P, Cao T. Reuse of recycled aggregate in the production of alkaliactivated concrete. In: Pacheco-Torgal F, Labrincha J, Palomo A, Leonelli C, Chindaprasirt P, editors. Handbook of alkali-activated cements, mortars and concretes. Cambridge, UK: WoddHead Publishing: 2014. p. 519-38.

[7] Bernal S, Rodríguez E, Kirchheim A, Provis J. Management and valorisation of wastes through use in producing alkali-activated. Cement materials. J Chem Technol Biotechnol 2016;91(9):2365-88.

[8] COM. 398 final. Towards a circular economy: a zero waste programme for Europe. Communication from the Commission to the European Parliament, the Council, the European Economic and Social Committee and the Committee of the Regions. Brussels, 2.7.2014. 2014.

[9] American coal ash association. 2016. https://www.acaa-usa.org/Publications Production-Use-Reports.

[10] Zhuang X-Y, Chen L, Komarneni S, Zhou C-H, Tong D-S, Yang H-M, et al. Fly ash-based geopolymer: clean production, properties and applications. J Clean Prod 2016;125:253-67.

[11] Collins F, Sanjayan JG, J.G. Workability and mechanical properties of alkaliactivated slag concrete. Cem Concr Res 1999:29:455-8.

[12] Collins F, Sanjayan JG, J.G. Effect of pore size distribution on drying shrinkage of alkali-activated slag concrete. Cem Concr Res 2000;30(9):1401-6.

[13] Mobili A, Belli A, Giosué C, Bellezze T, Tittarelli F. Metakaolin and fly ash alkali- activated mortars compared with cementitious mortars at the same strength class. Cem Concr Res 2016:88:198-210.

[14] Nematollahi B, Sanjayan J, Shaikh FUA. Comparative deflection hardening behavior of short fiber reinforced geopolymers composites. Constr Build Mater 2014;70(15):54-64.

[15] Shaikh FUA. Deflection hardening behavior of short fiber reinforced fly ash based geopolymer composites. Mater Des 2013;50:674-82.

[16] Nematollahi B, Sanjayan J, Uddin Ahmed Shaikh F. Matrix design of strain hardening fiber reinforced engineered geopolymer composite. Compos Part B Eng 2015;89:253-65.

[17] Korniejenko K, Fraczek E, Pytlak E, Adamski M. Mechanical properties of geopolymer composites reinforced with natural fibers. Procedia Eng 2016:151:388-93.

[18] ASTM C618-15. Standard specification for coal fly ash and raw or calcined natural pozzolan for use in concrete. ASTM International; 2015. West Conshohocken, PA, www.astm.org.

[19] ISTRICE Fili\&Forme Srl. Manufacturers of structural polymer fibers for concrete reinforcement. 2016. http://www.fibreistrice.com/index_en.html. Italy.

[20] Pacheco-Torgal F, Castro-Gomes J, Jalali S. Investigations on mix design of tungsten mine waste geopolymeric binder. Constr Build Mater 2008;22(9): 1939-49.

[21] B. EN, 1015-11: methods of test for mortar for masonry-Part 11: determination of flexural and compressive strength of hardened mortar. Brussels: European Committee for Standardization; 1999.

[22] Masi G, Rickard W, Bignozzi M, Riessen A. The effect of organic and inorganic fibres on the mechanical and thermal properties of aluminate activated geopolymers. Compos Part B Eng 2015;76:218-28.

[23] Choi W, Jang S, Yun H. Bond and cracking behavior of lap-spliced reinforcing bars embedded in hybrid fiber reinforced strain-hardening cementitious composite (SHCC). Compos Part B Eng 2017:108:35-44.

[24] Corinaldesi V, Nardinocchi A. Mechanical characterization of Engineered Cement-based Composites prepared with hybrid fibres and expansive agent. Compos Part B Eng 2016:98:389-96.

[25] Pakravan HR, Jamshidi M, Latifi M. Investigation on polymeric fibers as reinforcement in cementitious composites: flexural performance. J Industrial Text 2012;42:3-18

[26] Pakravan HR, Jamshidi M, Latifi M, Pacheco-Torgal F. Evaluation of adhesion of polymeric fiber reinforced cementitious composites. J Adhesion Adhesives 2012;32:53-60.

[27] JSCE (Japan Society of Civil Engineering). SF-4: method of test for flexural strength and flexural toughness of fiber reinforced concrete. Tokyo. 1984. p. $58-66$.

[28] Spadea S, Farina I, Carrafiello A, Fraternali F. Recycled nylon fibers as cement mortar reinforcement. Constr Build Mater 2015:80:200-9.

[29] Fraternali F, Farina I, Polzone C, Pagliuca E, Feo L. On the use of R-PET strips for the reinforcement of cement mortars. Compos Part B Eng 2013;46:207-10.

[30] Rots JG. Computational modeling of concrete fracture. PhD Thesis. The Netherlands: Delft University of Technology; 1988.

[31] Sena-Cruz JM. Strengthening of concrete structures with near-surface mounted CFRP laminate strips. PhD Thesis. Portugal: Department of Civil Engineering, University of Minho; 2004.

[32] Mastali M, Valente IB, Barros JAO. Development of innovative hybrid sandwich panel slabs: advanced numerical simulations and parametric studies. Compos Struct 2016;152:362-81.

[33] Mastali M, Valente IB, Barros JAO, Gonçalves D. Development of innovative hybrid sandwich panel slabs: experimental results. Compos Struct 2015;133: 476-98.

[34] Barros JAO, Costa GI, Ventura-Gouveia A. CFRP flexural and shear strengthening technique for RC beams: experimental and numerical research. Adv Struct Eng 2011;14:551-73.

[35] Pereira E, Barros AOJ, Camões A. Steel fiber-reinforced self-compacting concrete: experimental research and numerical simulation. J Struct Eng 2008;134:1310-21.

[36] Mastali M, Dalvand A. The impact resistance and mechanical properties of self-compacting concrete reinforced with recycled CFRP pieces. Compos Part B Eng 2016;92:360-76.

[37] Bazant ZP, Oh BH. Crack band theory for fracture of concrete. Mater Struct 1983; $16: 155-77$.

[38] Rots JG. Computational modeling of concrete fracture. PhD Thesis. Delft, The Netherlands: Delft University of Technology; 1988.

[39] Oliver J. A consistent characteristic length for smeared cracking models. Int J Numer Methods Eng 1989;28:461-74.

[40] Borst R. Computational methods in non-linear mechanics. Part 2: physical non-linearity. Delft: Delft University of Technology; 1991. Report 25-2-91-206.

[41] Cervenka V, Pukl R, Ozbolt J, Eligehausen R. Mesh sensitivity effects in smeared finite element analysis of concrete fracture. In: Wittmann F, editor. Proceedings of FRAMCOS-2 - fracture mechanics of concrete structures Zurich; 1995.

[42] Sousa C, Leitão L, Faria R, Azenha M. A formulation to reduce mesh dependency in FE analyses of RC structures under imposed deformations. Eng Struct 2017;132:443-55.

[43] Fascetti A, Feo L, Nisticò N, Penna R. Web-flange behavior of pultruded GFRP Ibeams: a lattice model for the interpretation of experimental results. Compos Part B Eng 2016;100:257-69. 
[44] Caggiano A, Gambarelli S, Martinelli E, Nisticò N, Pepe M. Reinforced experimental characterization of the post-cracking response in hybrid steel/polypropylene fiber-reinforced concrete. Constr Build Mater 2016;125:1035-43.

[45] Mastali M, Dalvand A. Fresh and hardened properties of self-compacting concrete reinforced with hybrid recycled steel-polypropylene fiber. Mater Civ Eng (ASCE) 2017. http://dx.doi.org/10.1061/(ASCE)MT.1943-5533. 0001851.

[46] Martinelli E, Caggiano A, Xargay H. An experimental study on the postcracking behaviour of hybrid industrial/recycled steel fiber-reinforced concrete. Constr Build Mater 2015;94:290-8.

[47] Caggiano A, Cremona M, Faella C, Lima C, Martinelli E. Fracture behavior of concrete beams reinforced with mixed long/short steel fibers. Constr Build Mater 2012;37:832-40.

[48] Mastali M, Ghasemi Naghibdehi M, Naghipour M, Rabiee M. Experimental assessment of Functionally Graded Reinforced Concrete (FGRC) slabs under drop weight and projectile impacts. Constr Build Mater 2015;95:296-311.

[49] Ožbolt J, Lacković V, Krolo J. Modeling fracture of fiber reinforced polymer. In J Fract 2011;170:13-26.

[50] Ožbolt J, Reinhardt HW. Numerical study of mixed mode fracture in concrete. Int J Fract 2002;118:145-61.

[51] Gambarelli S, Nisticò N, Ožbolt J. Numerical analysis of compressed concrete columns confined with CFRP: microplane-based approach. Compos Part B Eng 2014;67:303-12.

[52] Nisticò N, Ožbolt J, Polimanti G. Modeling of reinforced concrete beams strengthened in shear with CFRP: microplane-based approach. Compos Part B Eng 2016;90:351-64.

[53] Mastali M, Dalvand A, Sattarifard A. The impact resistance and mechanical properties of the reinforced self-compacting concrete incorporating recycled CFRP fiber with different lengths and dosages. Compos Part B Eng 2017;112: 74-92. 